ANTED STATES DEPARTMENT OF THE INTERIOR

\title{
GEOLOCICAL SURVEY
}

$\left(\frac{1}{(-6)}\right)$

PRÉLIMINARY GEOMAGNETIC DATA

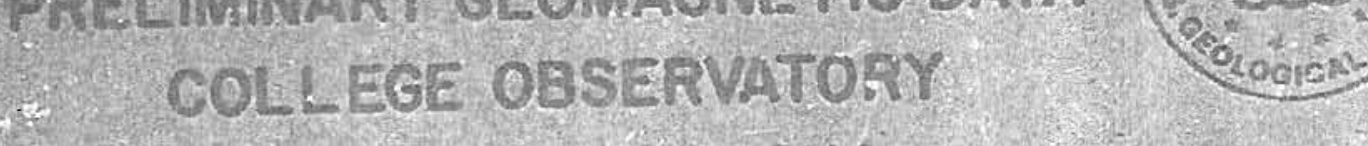

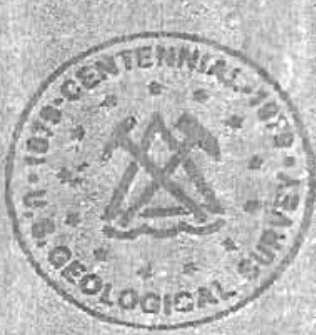
FAIRBANKS, ALASKA

JWUARY 1979 OPENFILEREFORT 79-300A

$x$

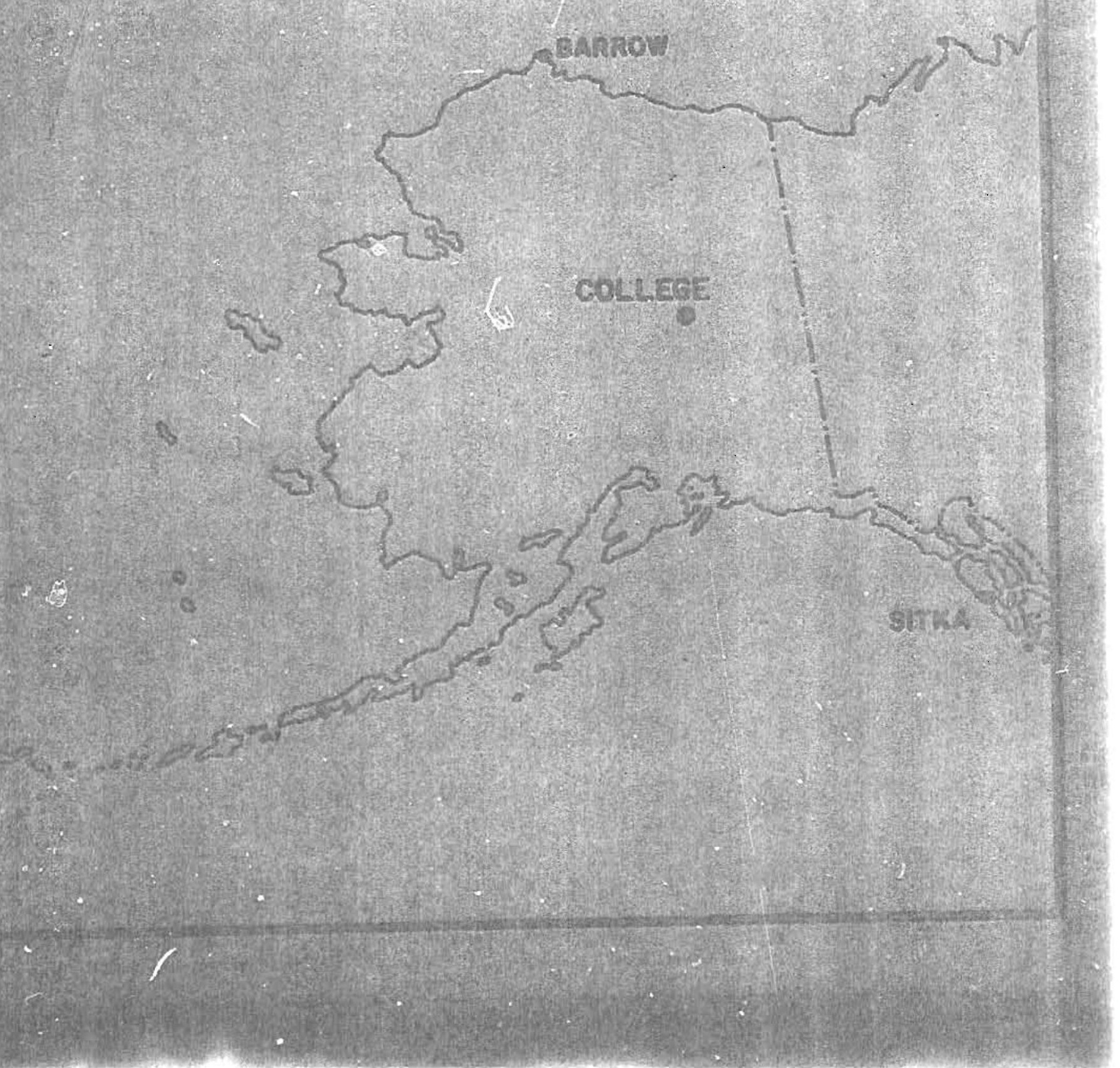




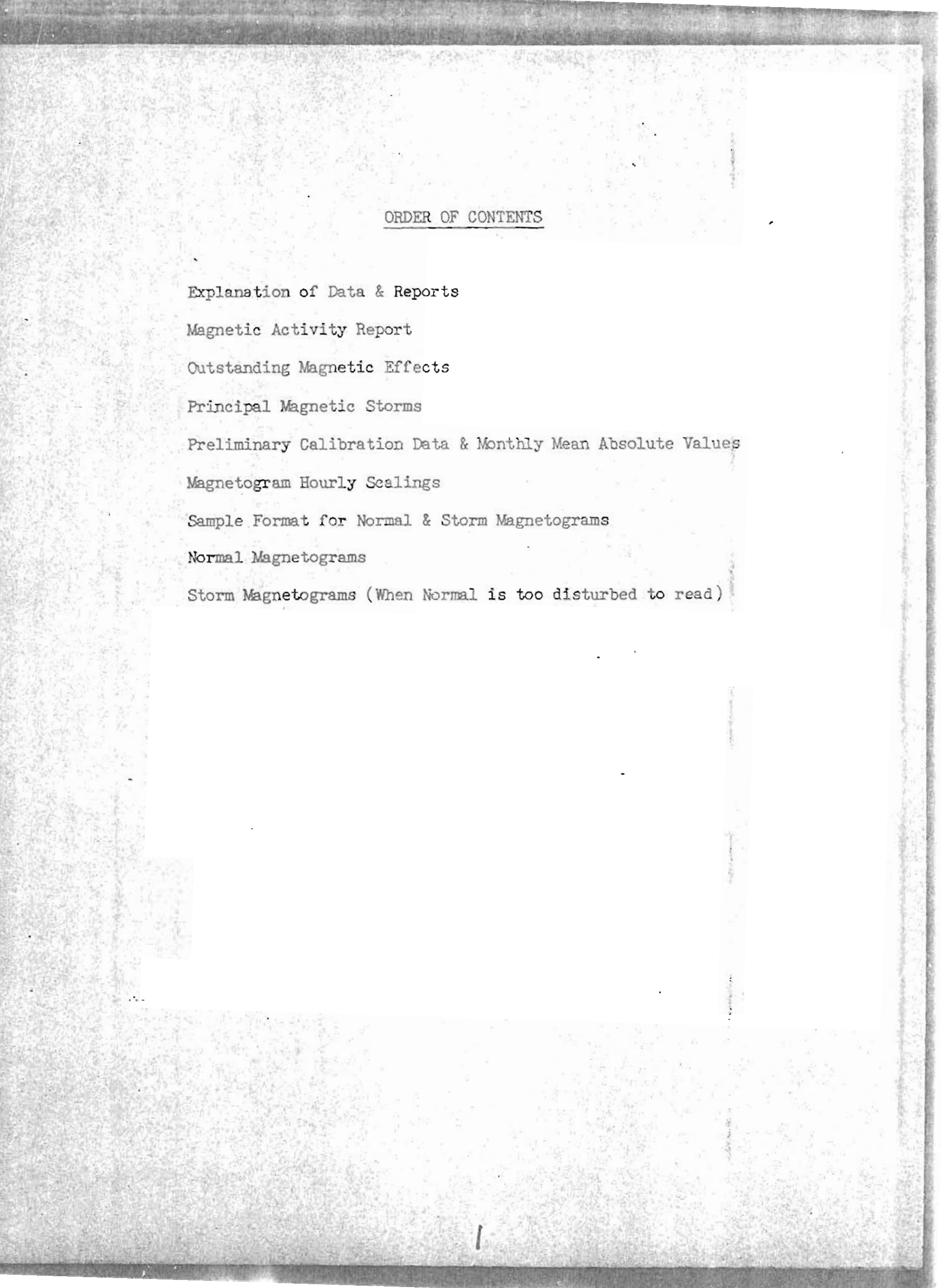


THIS REPORT WAS PREPARED UNDER THE DIRECTION OF JOHN B. TOWNSHEND. CHIEF OF THE COLLEGE OBSERVATORY WITH THE ASSISTANCE OF OBSERVATORY STAFF MEMBERS J. E. PAPP, ASST. CHIEF. AND S. P. TILTON, AND IN COOPERATION WITH THE GEOPHYSICAL INSTITUTE OF THE UNIVERSITY OF ALASKA. THE COLLEGE OBSERVATORY IS A. PART OF THE BRANCH OF ELECTROMAGNETISM AND GEOMAGNETISH OF THE U.S. GEOLOGICAL SURVEY,

INTODNCTION

Toe prelininary geonagnetic data included here 15 made avaliable to aclentific persontel and organizations, as part of a copperstive effort and on a datin exchange basis because of the early need by sone users. To avold delay, 321 of the data 15 copied from orialtu? forna processed at the observacory; thereprore it should be regarded as preliminary. Inquirles about this repor. or about the College Observatory stould be addresned to:

Chlef, college Obsertazory

19.S. Geological Survey

Yukon Drive on Kest Ridge

Fairbarks, Alaska 99701

Requests for coples of the nagnetorrams exispt for the crirtont month should be addressed "o:

Vorld Dnta Center A-NOAS

Environmentris Dnta Service

Boulder, Colorado 80302

Norms 2, Storm, and Rapid Run maznetorrans snd appropriate colibracion dain are processed dat2y $\mathrm{s}$ the observarory and are avaliable for aralysis or copyling. Aloo availsble are mean hourly scellag, s-Indices, - selected magnetic phenomens reports, and

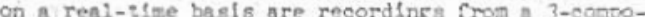
nent rluxgsice monetometer and. F-component proton. nagnetomices.

\section{Magnet1c Actintiy}

the K-Index The $\mathrm{g}$-Index is a logarithan's measure. ment of the range of the most disturbed component ( $D$ or H) of the Reomametic cleid for elght intervals beginning $0000-0300,0300-0600,2100-24,00$ UT. It is a messure of the dsfference between the highest and lowest deviation rrom a snooth curve wo be expecied for a canponent on s angretically aulet dny, w!thin a three hour interval.

The Eoulvalene Dn12y Amplisude, AX. The R-index.

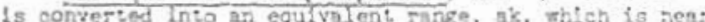
the center of the limiting gamms ringes for a fiven k. The average of the elght values 1 s called equivalent daily amplivude AK. The unlt IO r has been chosen so $a$ not to give the 111usion of an accuracy not fustifted.

The schedule for converting germs range to $k$. and $x$. nk is as rollowe

\begin{tabular}{r} 
Gemm Pange \\
\hline $0<25$ \\
$25 \div 50$ \\
$50<100$ \\
$100<200$ \\
$200 \div 350$ \\
$350<600$ \\
$600<1000$ \\
$2000<1650$ \\
$1650<2500$
\end{tabular}

\begin{tabular}{c}
$\mathbf{K}$ - Index \\
\hline 0 \\
1 \\
2 \\
3 \\
4 \\
5 \\
6 \\
7 \\
3 \\
9
\end{tabular}

$\frac{a \times d}{0}$
3
7
15
27
48
80
140
240
400

The Magrotic Dnily Character Figure, C. To each Universel day a character is assigped on the basis $C=0$, if 12 is quies; $C=1$ if lt 1 a moderstely disturbed; $C=2$ if 1 : 1 s grentiy disturbed. The

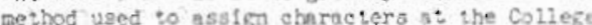
Observasory is baged on AK as followr:

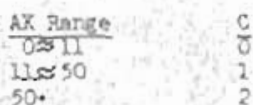

Poutine assigrtent of $\mathrm{C}$ men discontinued at College on Jamuary i, 1976.
OPSERWATORY FOCATION

the College Observacory, operaied by the U. S. Goolczical Survey, fo loceted nt the Unlvernfty of Llaskn. Folrbanks, Ainsta. It is nme the hurorn? Cone and the northern ilate of the workd's freetert

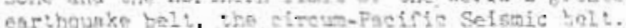
Although the obserrarory' o baste operntion 15 in geonagnetism and zei mology, is coopertud? with other

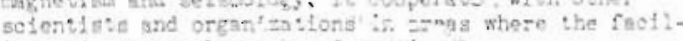
I:y and permonsel onn be of service.

The observatory is gre of three operated by the "SCS in Alarikn. The othars ore locstod ne tharrow and St:kat.

The posiclon of the observetory gite is:

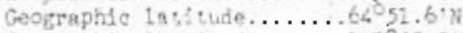

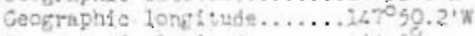

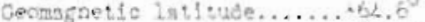

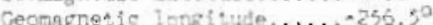

Eevntion..............200 meter:

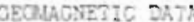
fun records were zevilued si the obervatory for selected magnetic phonozero und the events identifled rere formarded to the IUGG Conniasion on Magnetic

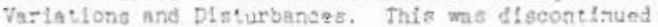

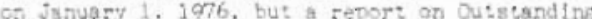
Wonetio Effects is prepared monthly for thit report.

Prinolpal Magne:io storas

Grodual and budden comencemen: magne: 10 distur-. bances with at leas: one K-index of 3 or grester, whick are believed to be part of g world-wide disturbance. are classified as princlpol magnetlc storna. The sine of the atora beginning and ending; direc:ion and anplivde of sudden cormencenents: perlod of maximum activity: and atorn rane dre reported. Wonchly reports

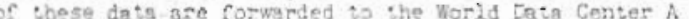
In Bogider, Cotorgdo.

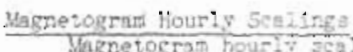

Magnetocrat hourty zca: ings are uvornges for sucesalve pertodn of one hour fo- the D. H, and th elements. The value in she colum, headed "01" is the avarage for the hour berinning 000 and ending 0100 . Note that the values on the gcslint shoets are in ?oth of an with the decinal point onfted. The user of these sonlings ahould keep in nind thst the tabular values are hour 13 means and 10 he 18 interested in the decalled norpholory of the matrealo Cleld, he should refer directiz to the nagnetograms.

\section{Magnetograns}

The norinal mognetograms in this report sre teptoduced at sbout one-thif the alze of the origingls. Prediminnry base-ilne rilues and scale values adopted for use with the orfeingi anenetorrame are snoluded. For dove when the masnetle cleld is to disturbed for tho Nornal. magnetogran to be reshih? A. Stornt mngnetograss are repro¿uced.

Absolutes. Base-ines, and Sonle Values

To deteralne the abrolute value of the manets cleld fron the houriy means or Gron polnt scnlines the rollowing equations should be ured:

$D=B_{D}+d \cdot S_{D} ; \quad$ if $=B_{-2}+h \cdot S_{H} ; \quad Z=B_{Z} * z \cdot 5_{Z}$

where $D$, H, and 2 ste sbocilute values:

BD. By and Bqare bsse-2ine values:

SD. Sy and $S_{z}$ are scale valueg;

nd $d$, ho and $z$ sre scolings in mllimeters. 


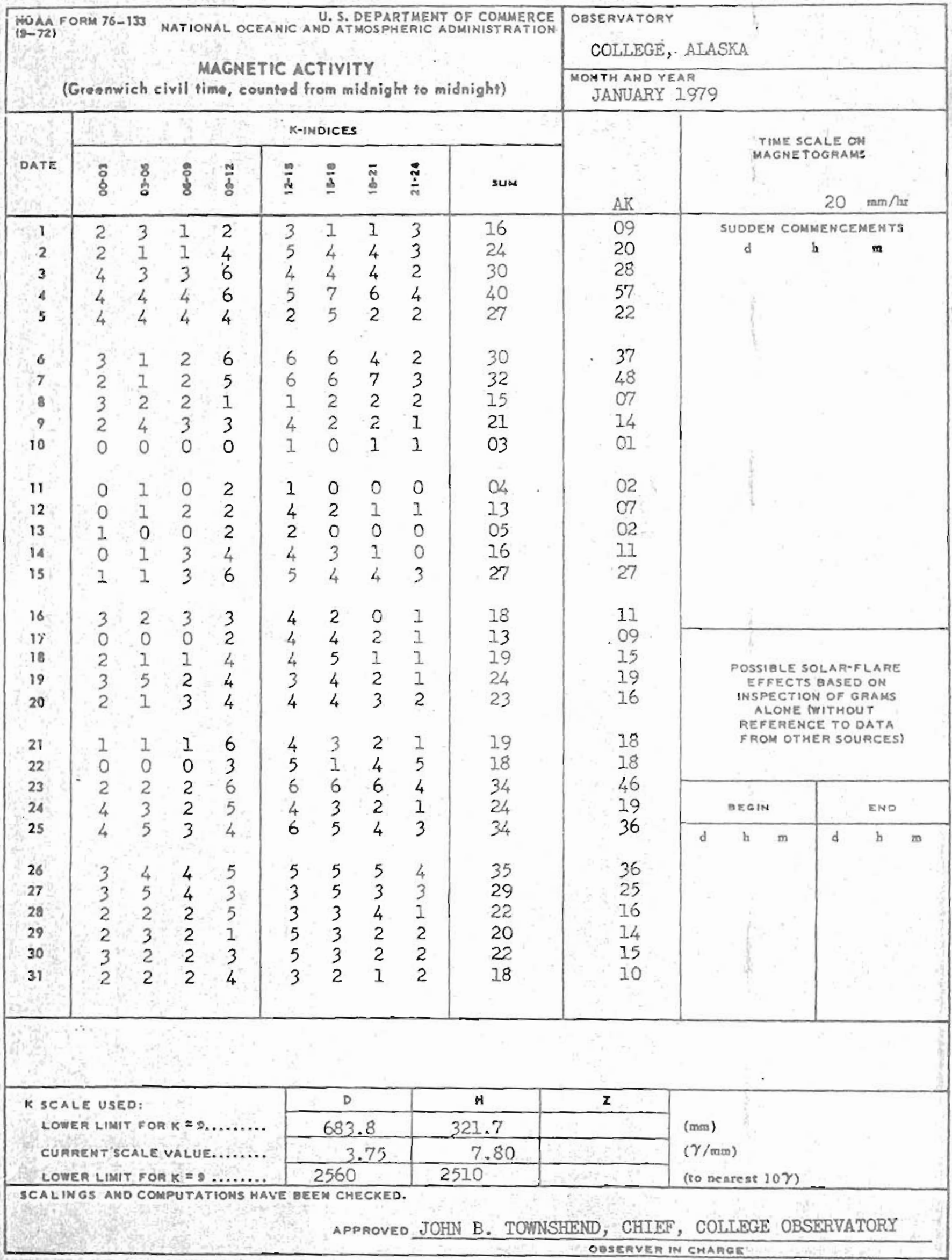




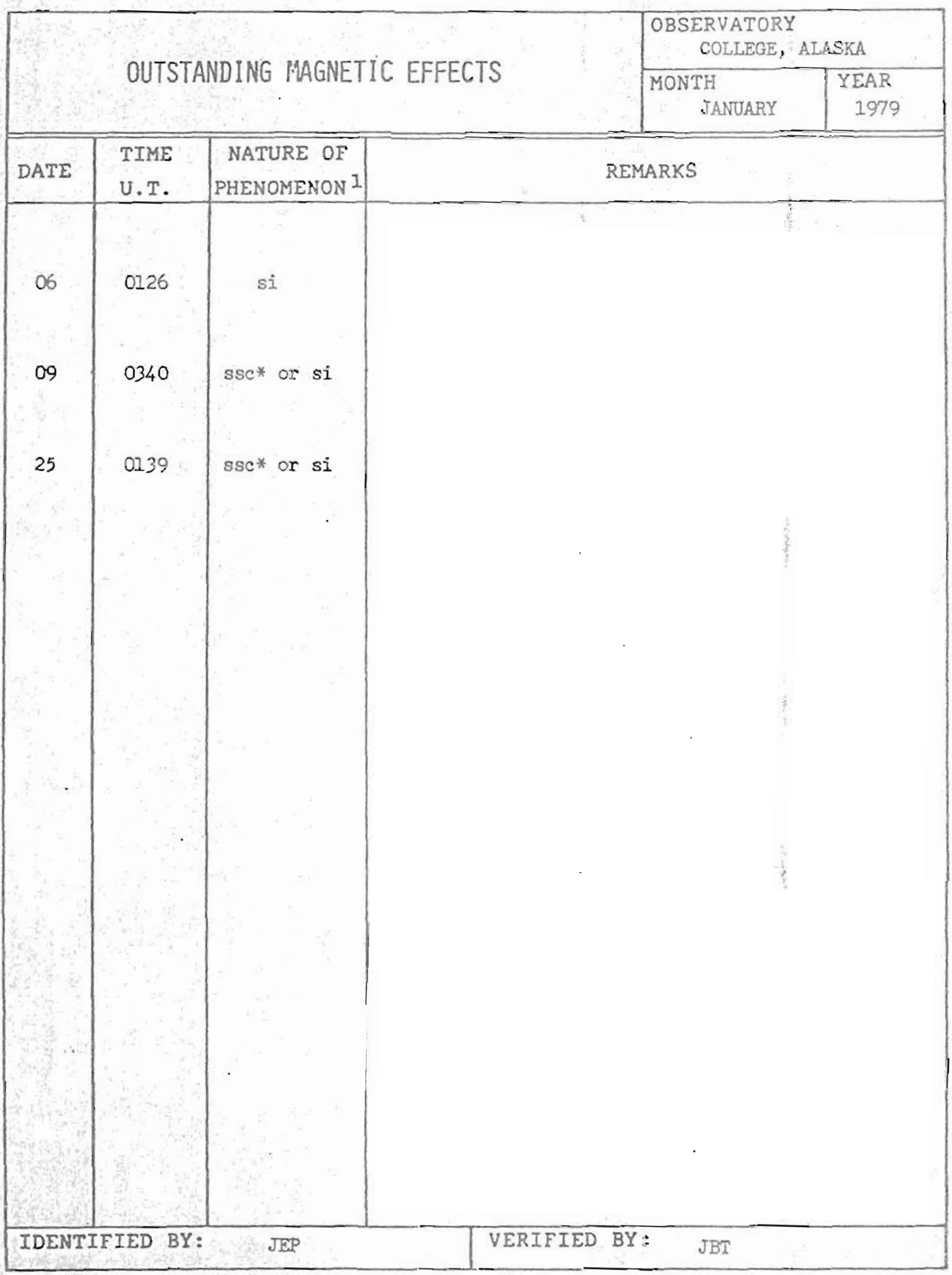

1. NATURE OF PHENOMENON: ssc, ssc* , si, sin, b, bp, bs, bps, pc1, pc2 - - pc5, pg, pi 1, pi 2, sfe. 


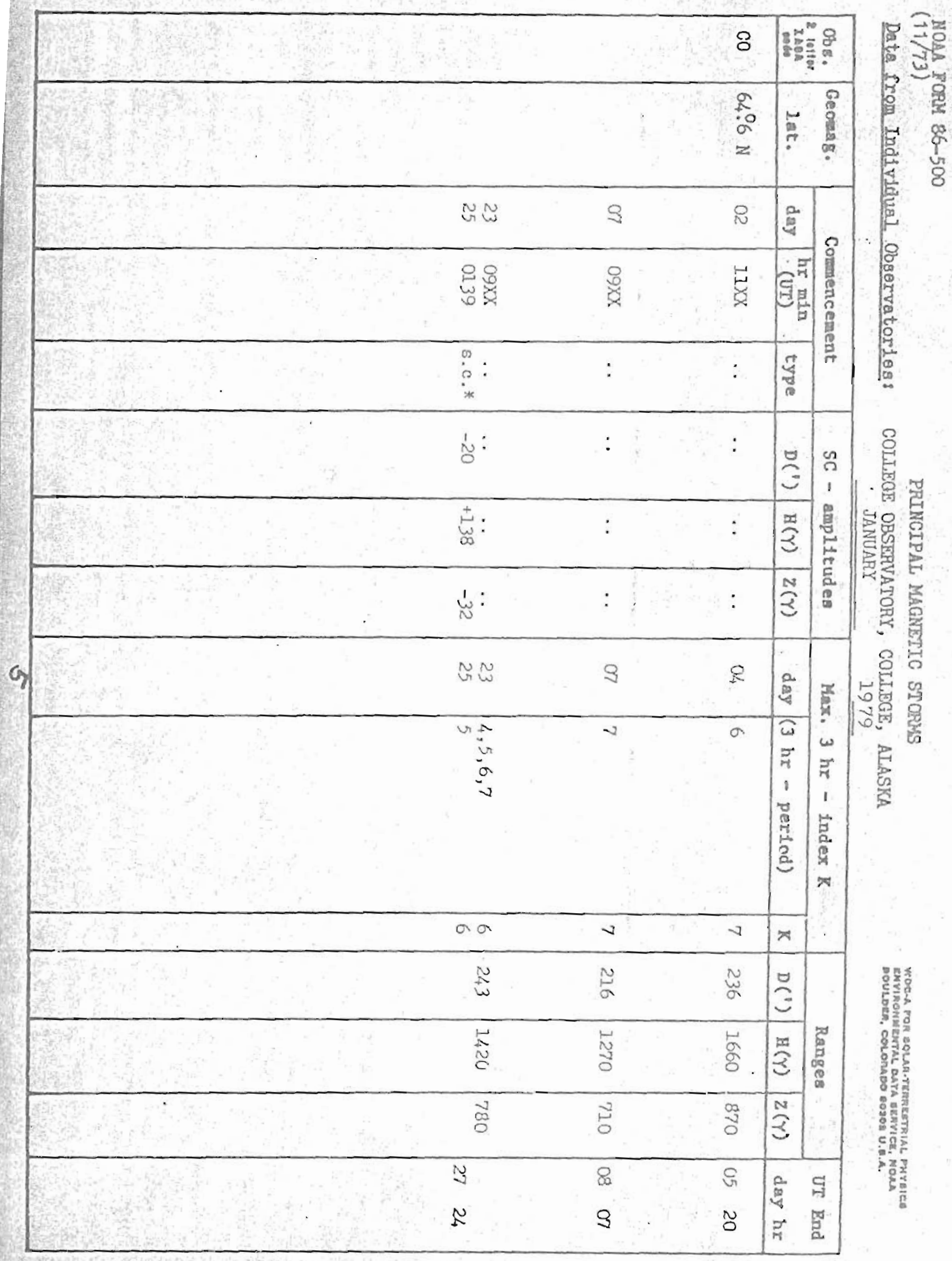




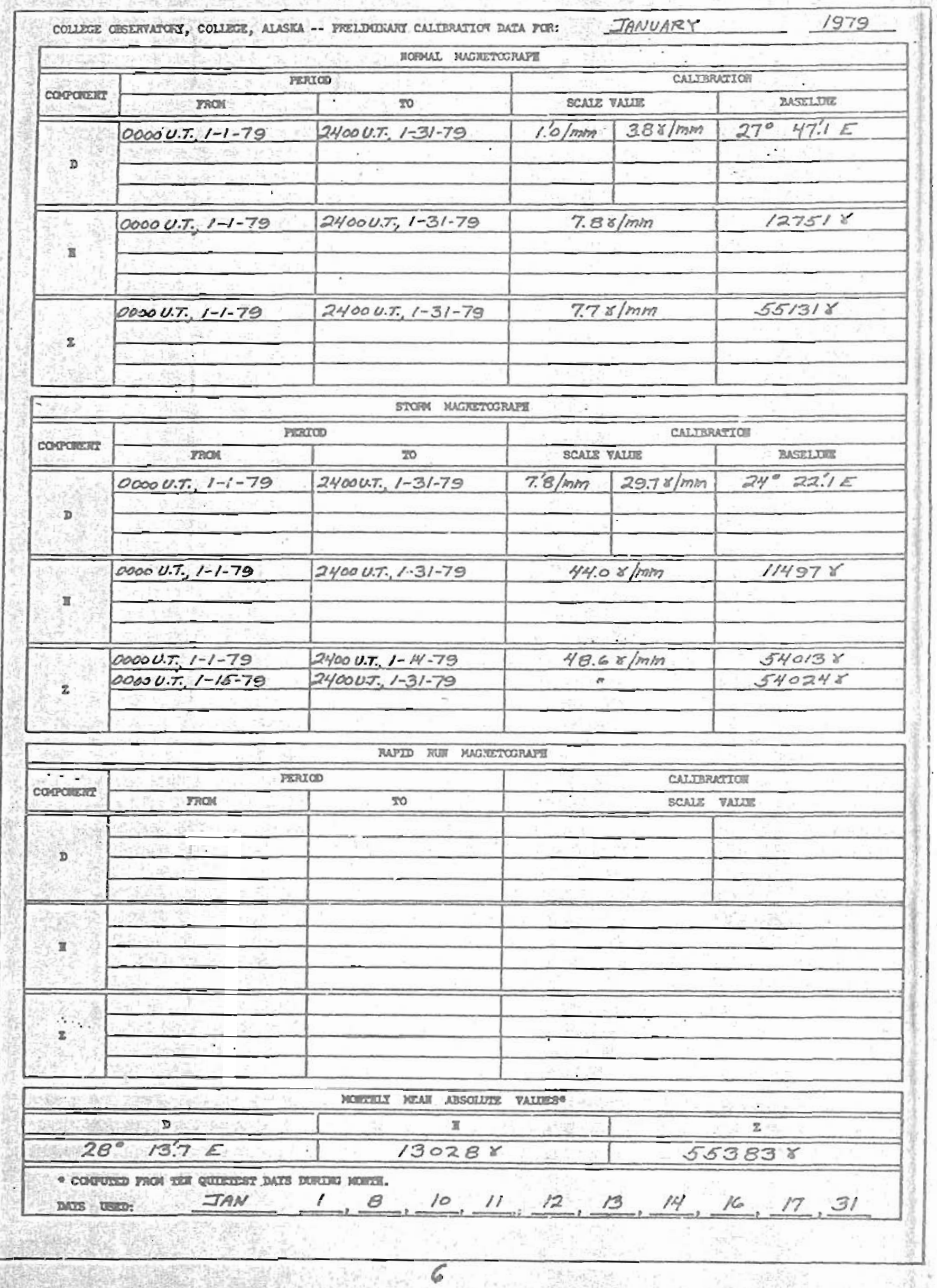




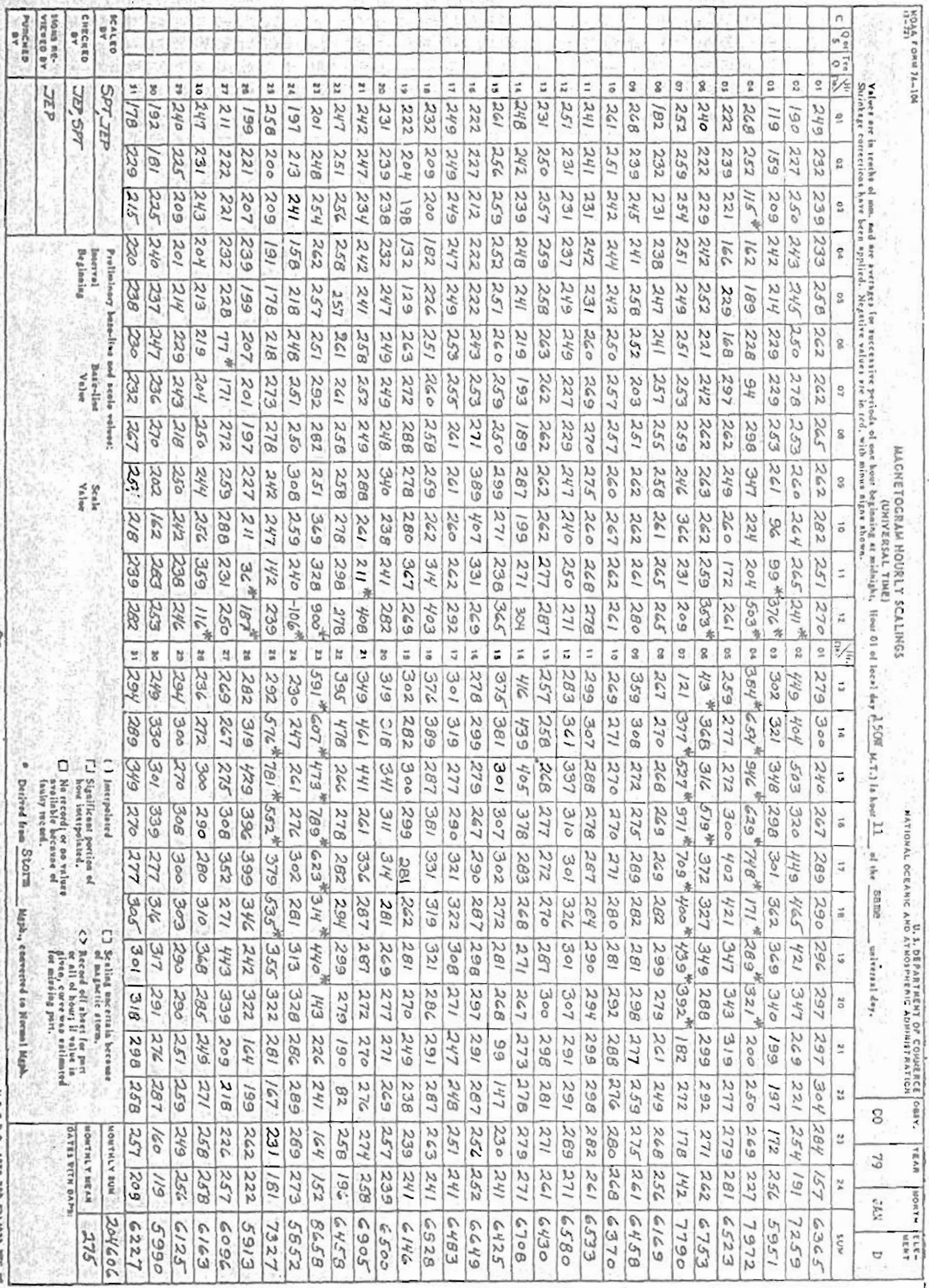




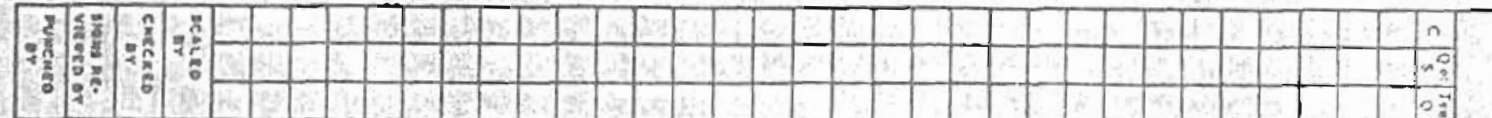

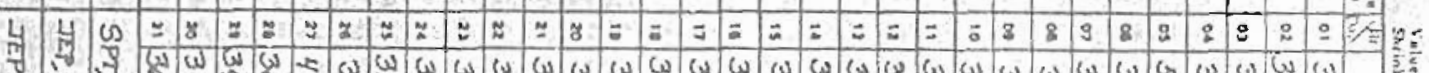

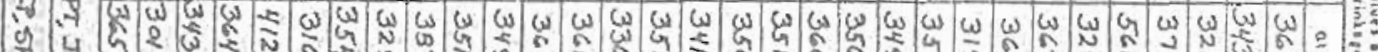

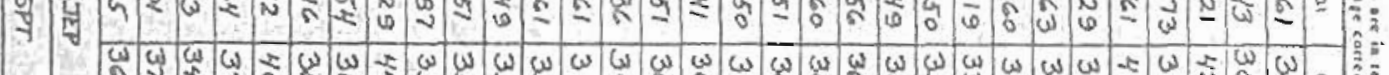

人.

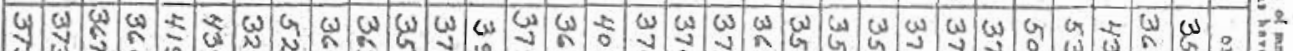

(1)

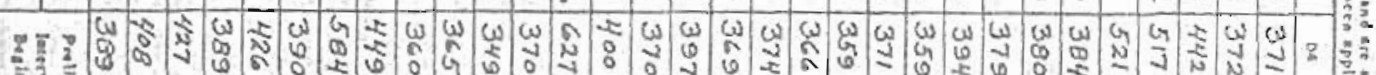

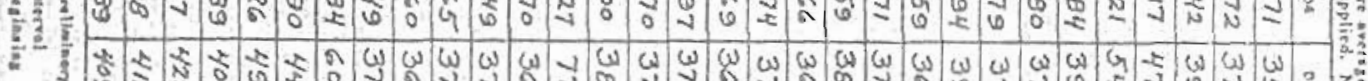

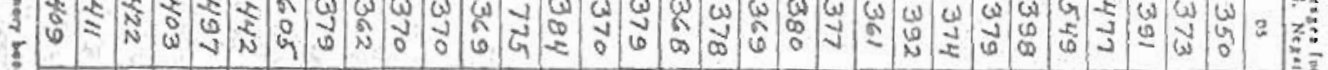

S

<.:

1

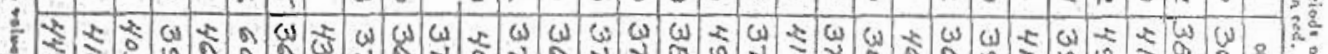

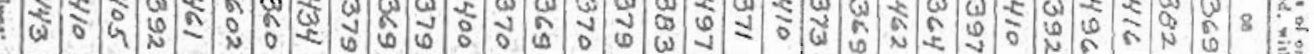

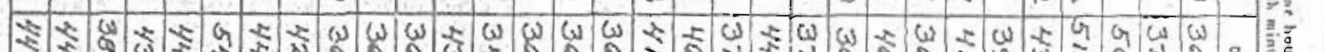

ร क०

今:

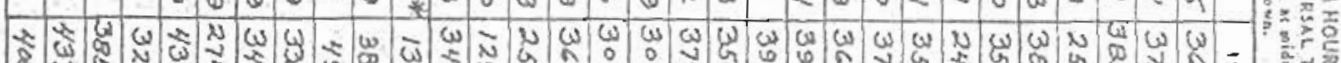

8 W

$\omega$ W

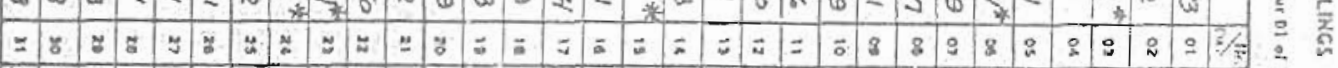

Wक

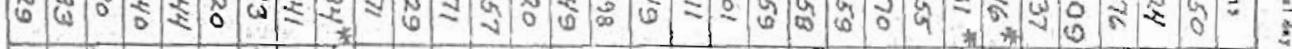

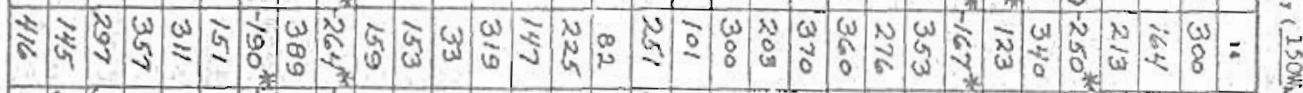

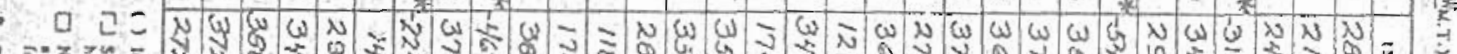

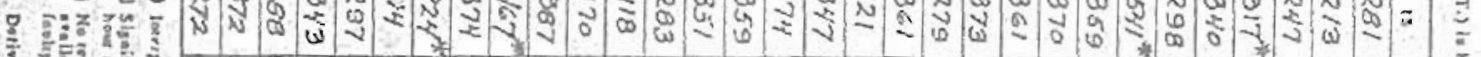

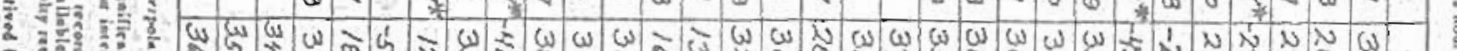

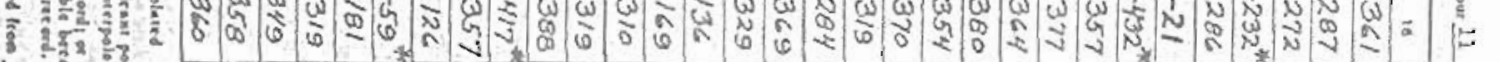

W : B?

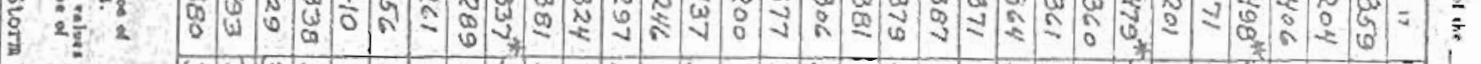

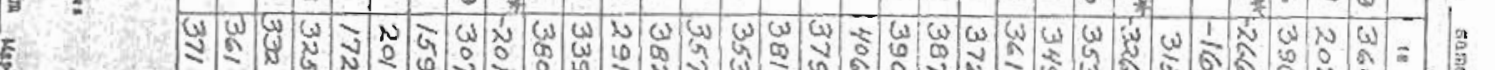

2.5 G

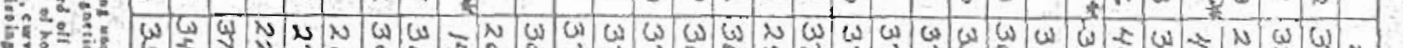

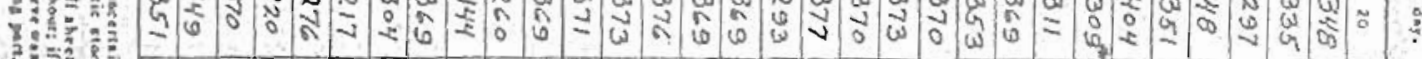

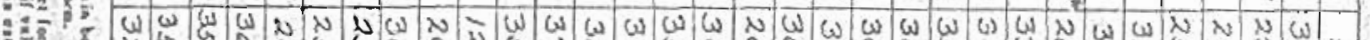

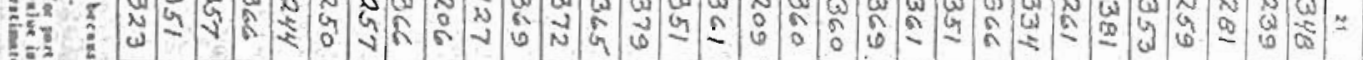

$\omega \omega \omega \omega N \omega-N \omega \omega \omega \omega \omega N \omega \omega \omega \omega \omega \omega N \omega N N \omega$.

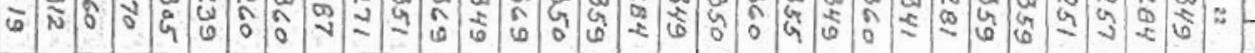

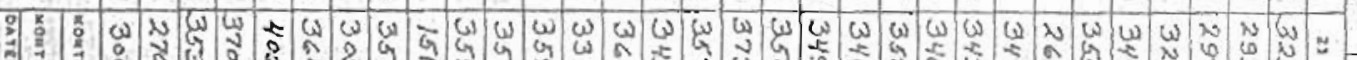

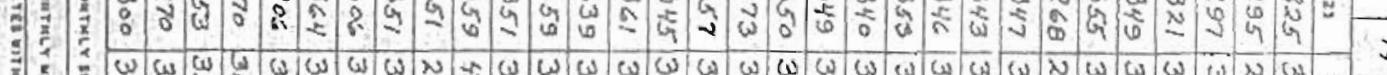

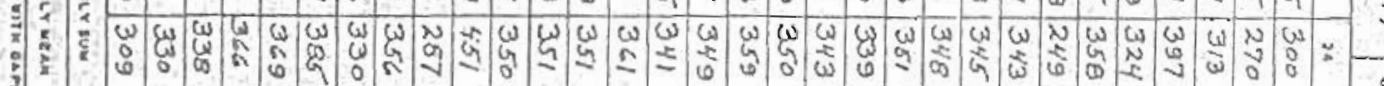

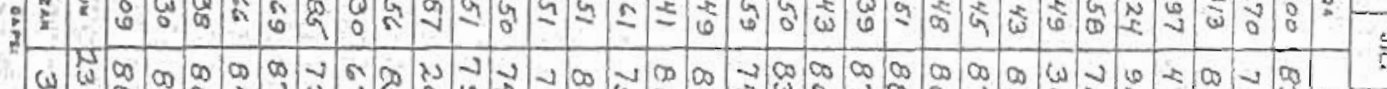

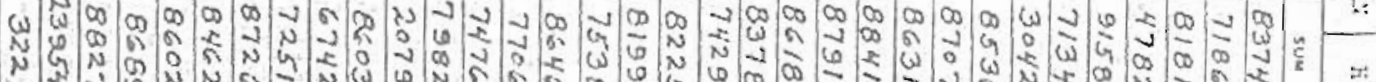




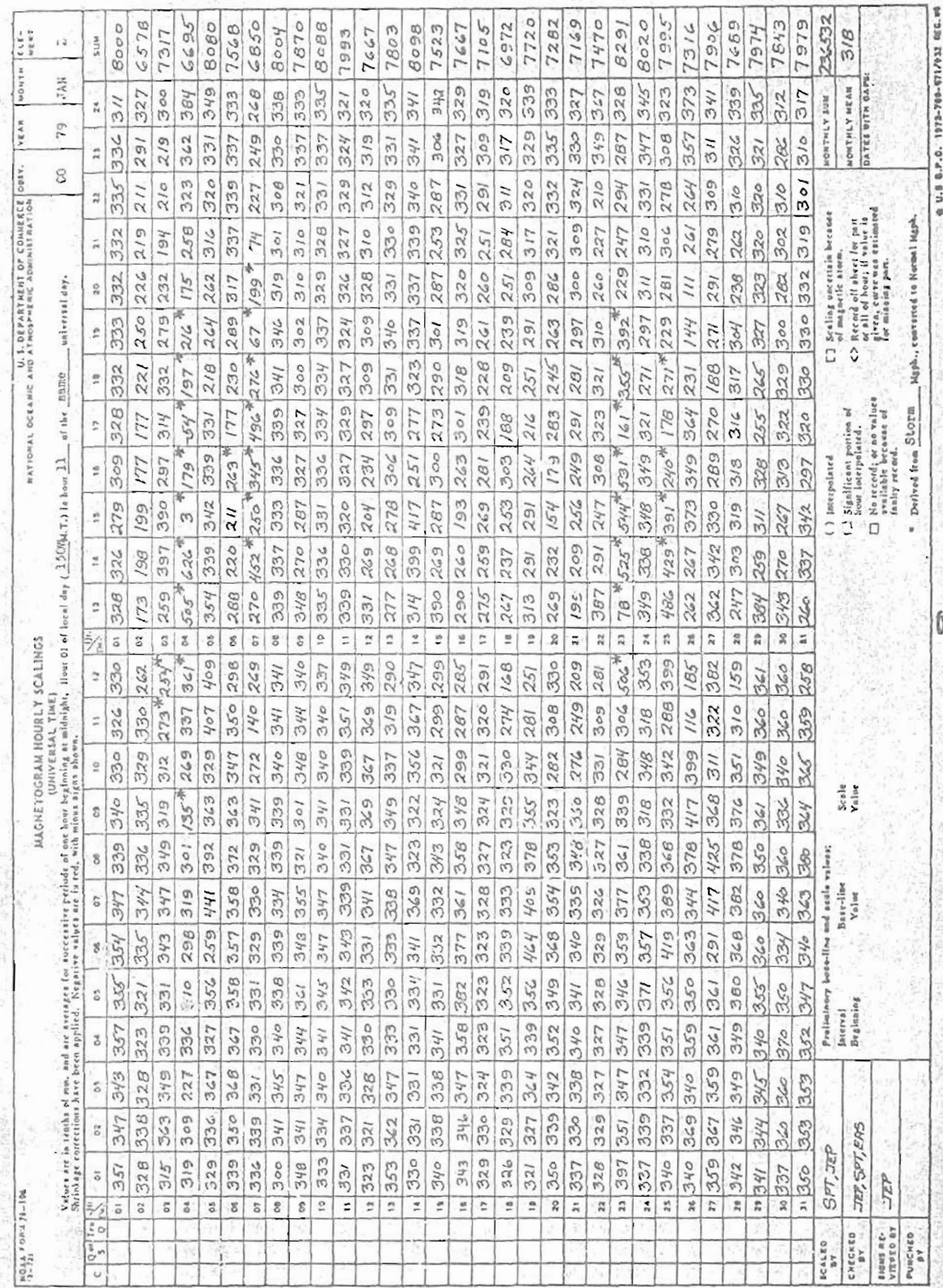




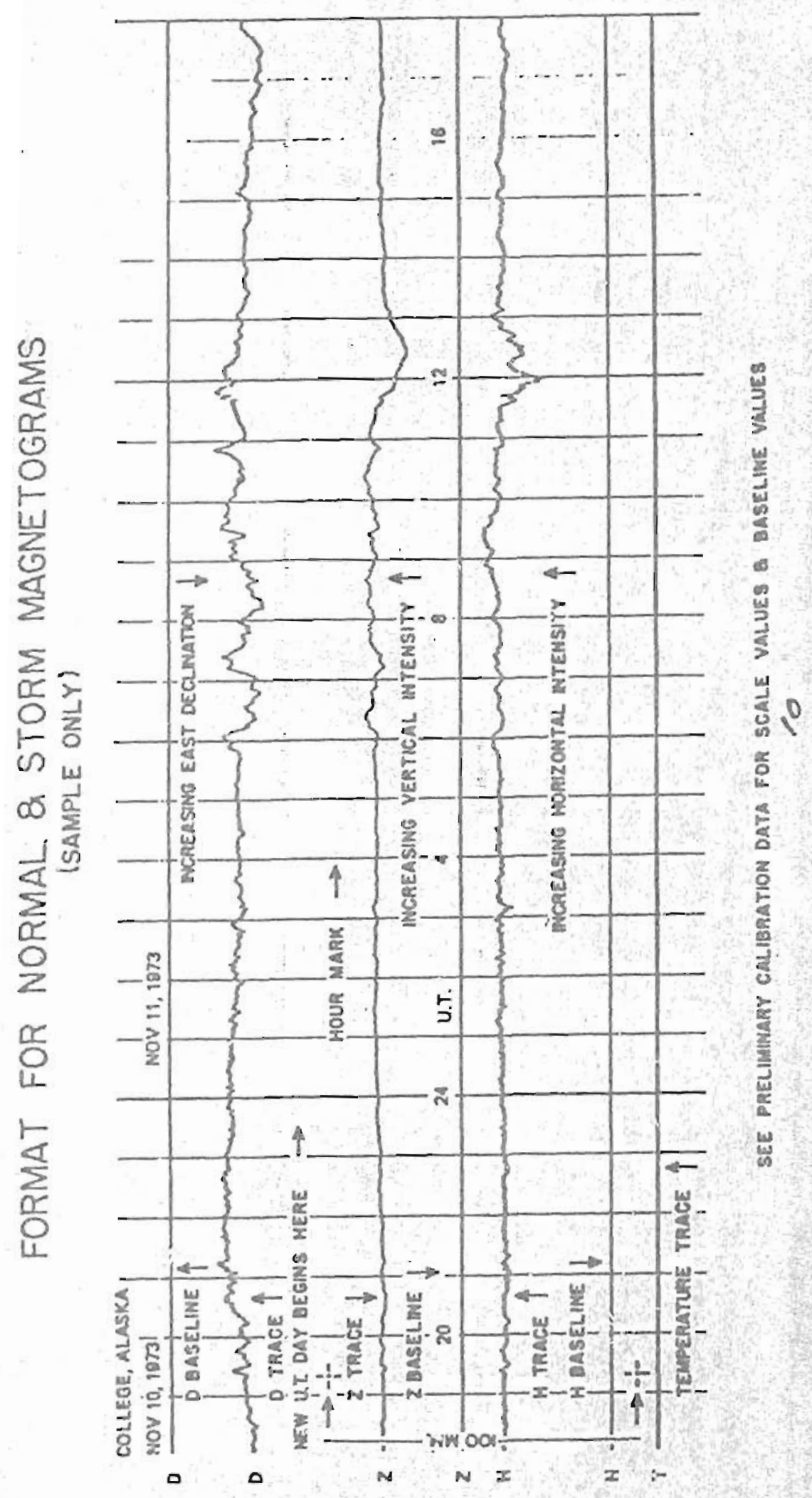




\section{II}

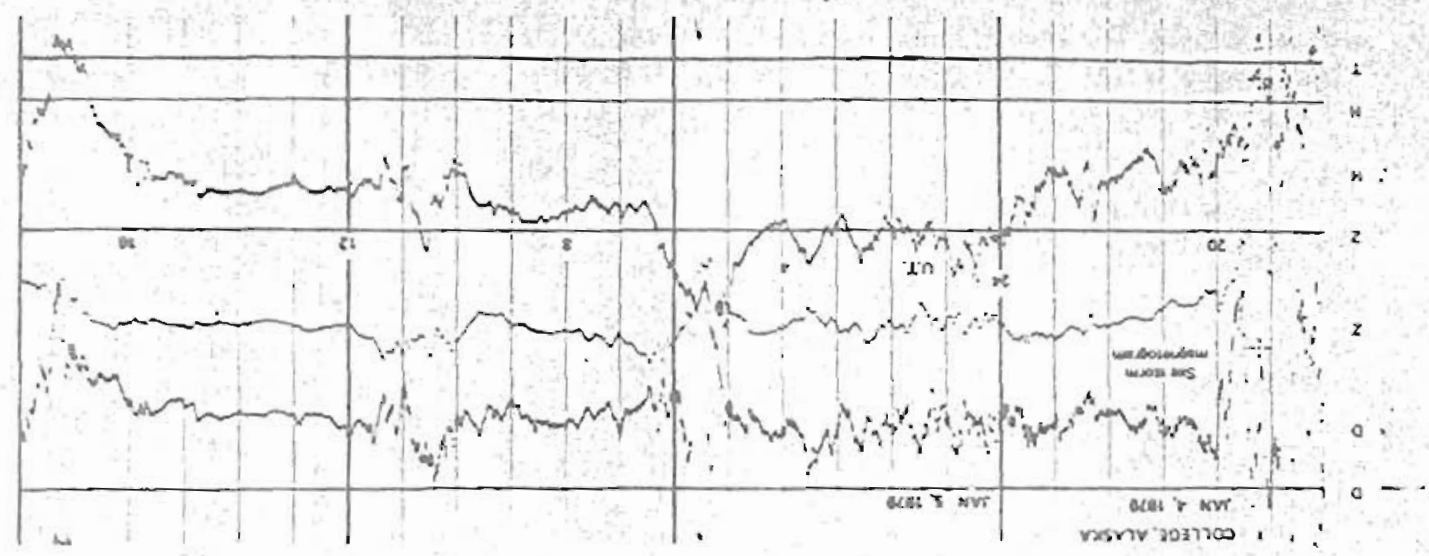

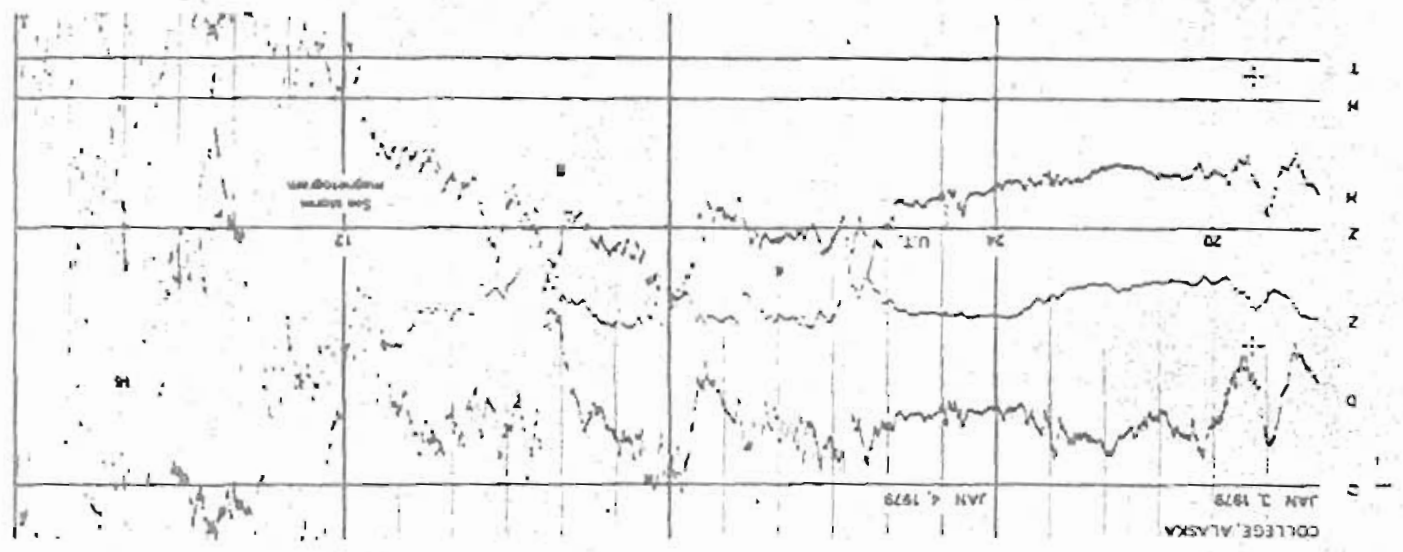

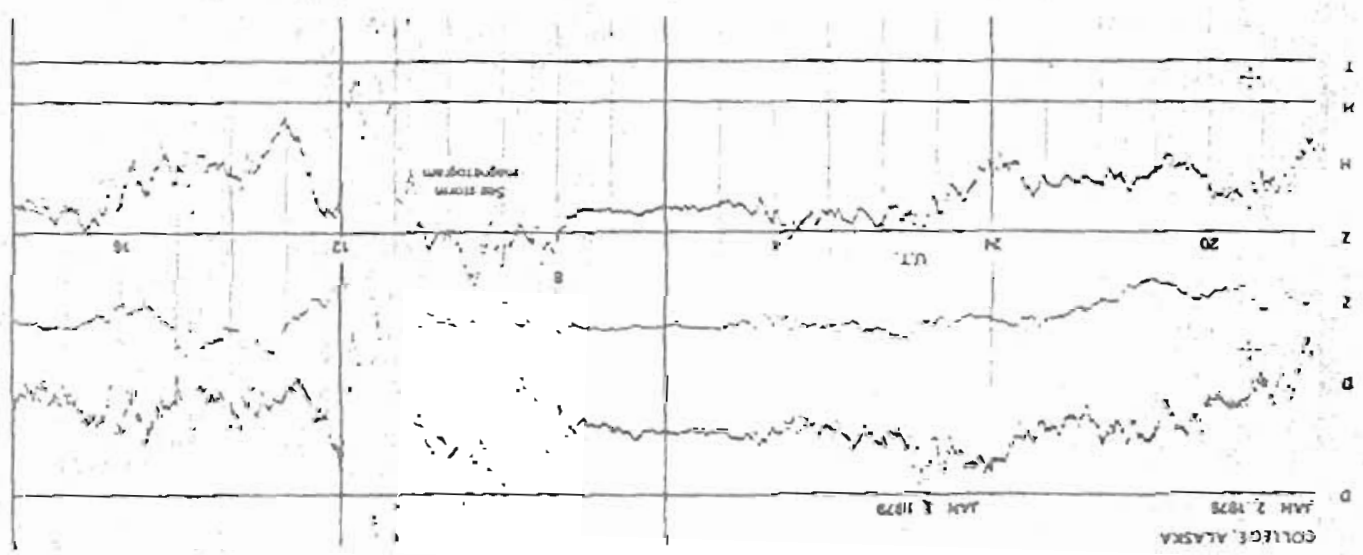

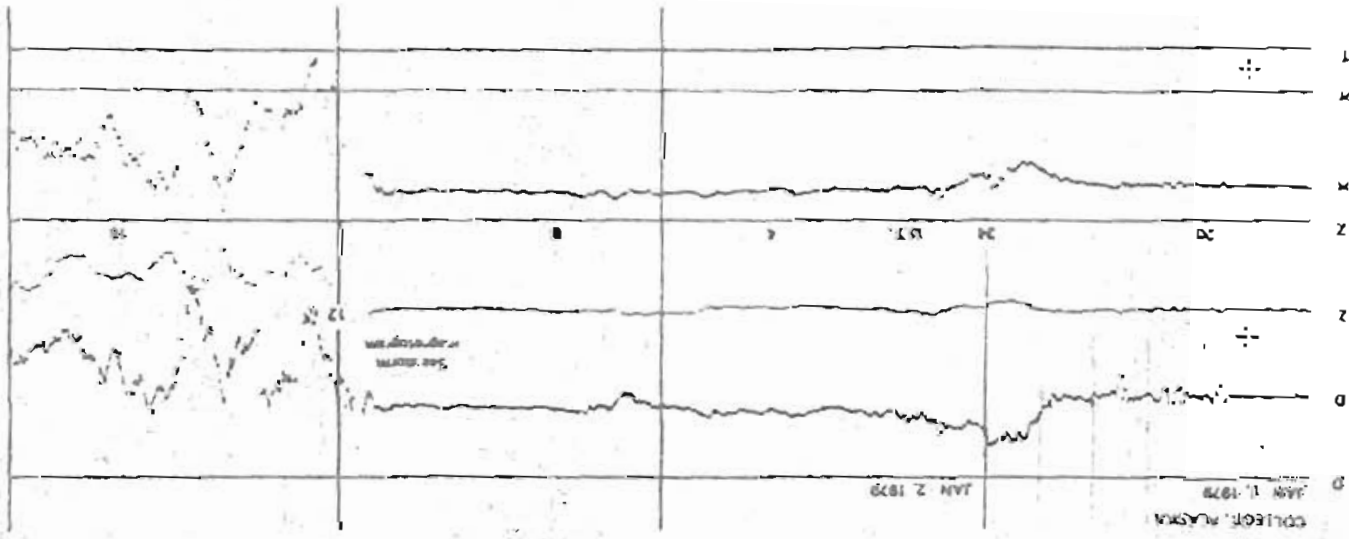




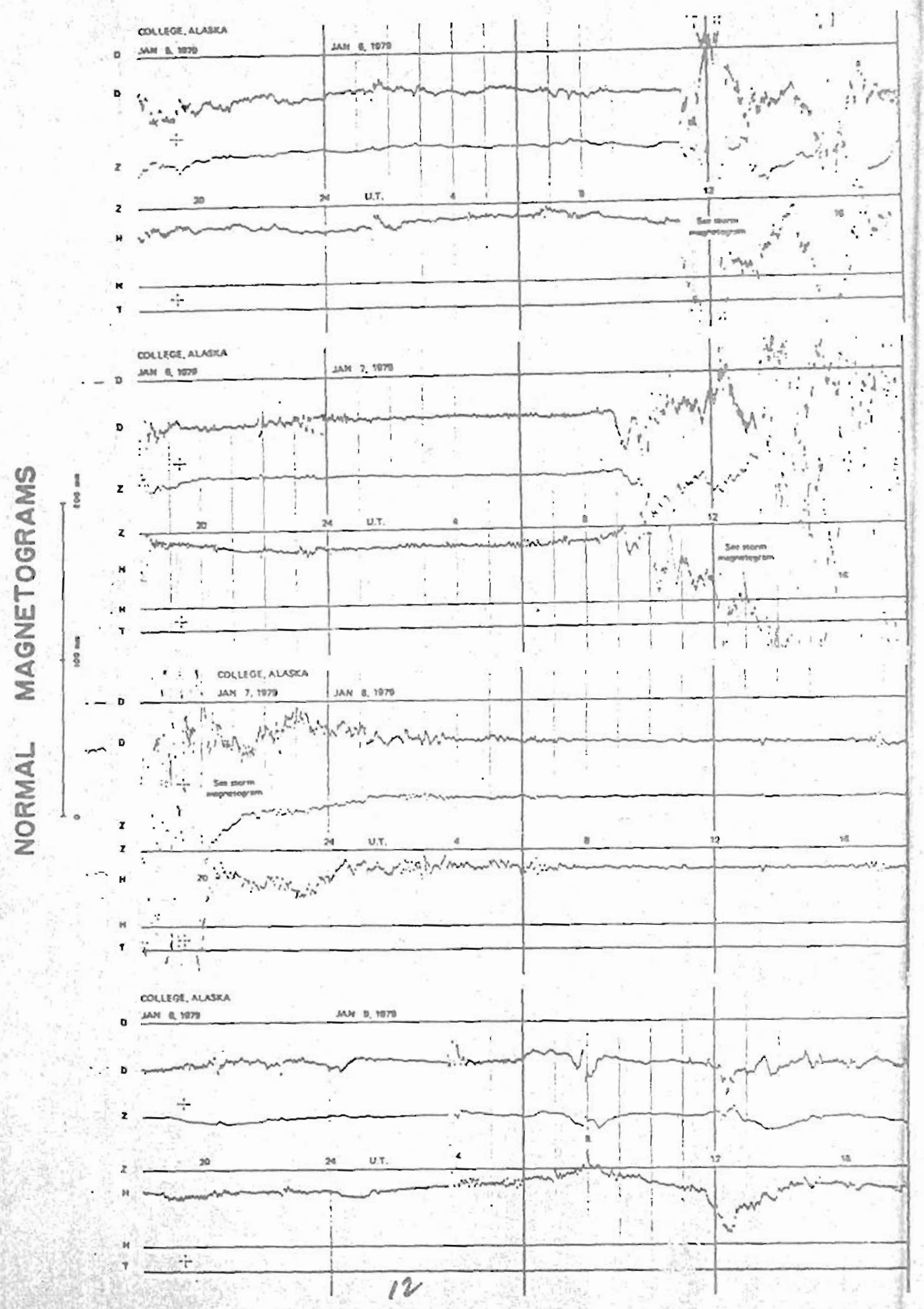




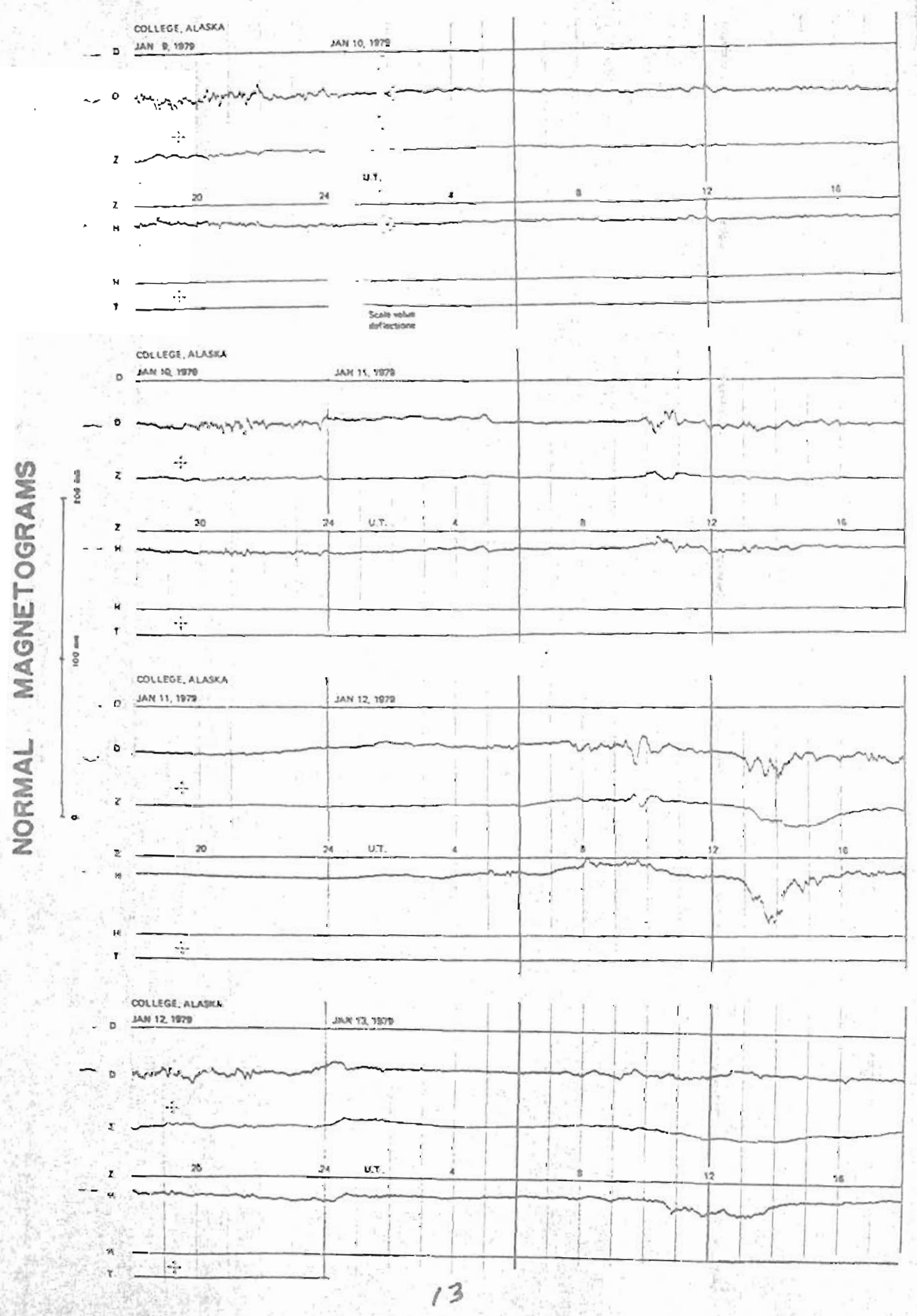




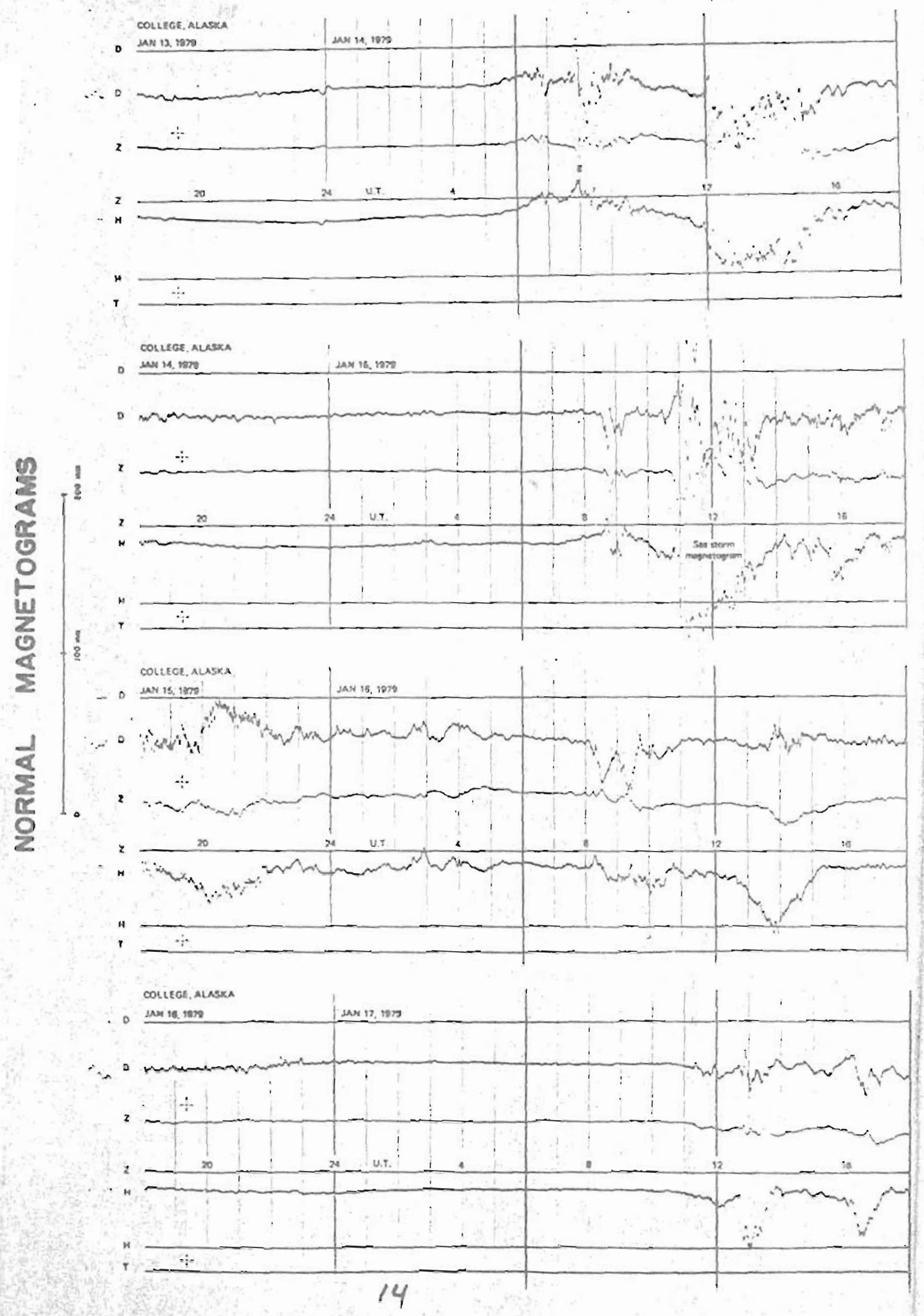




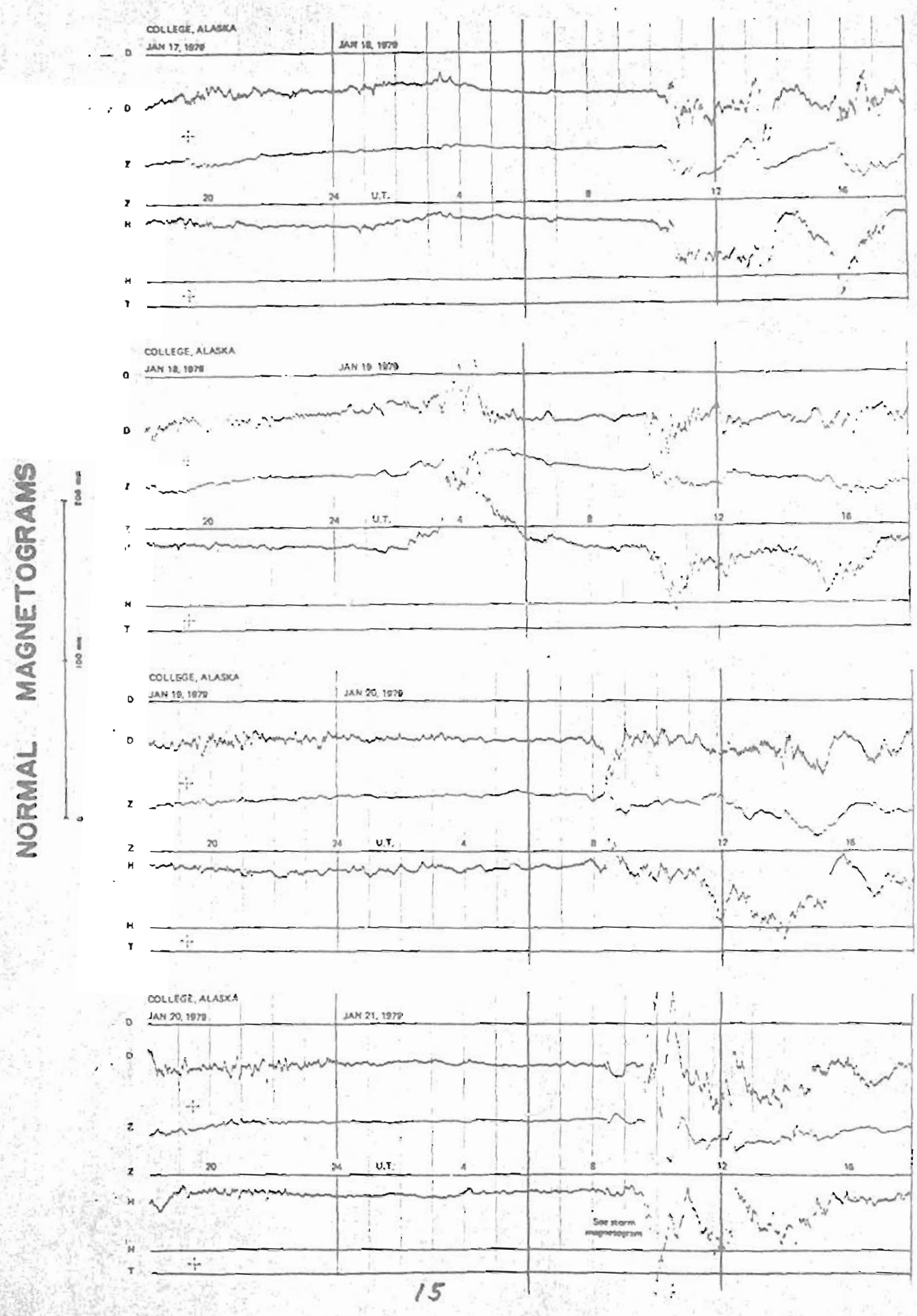




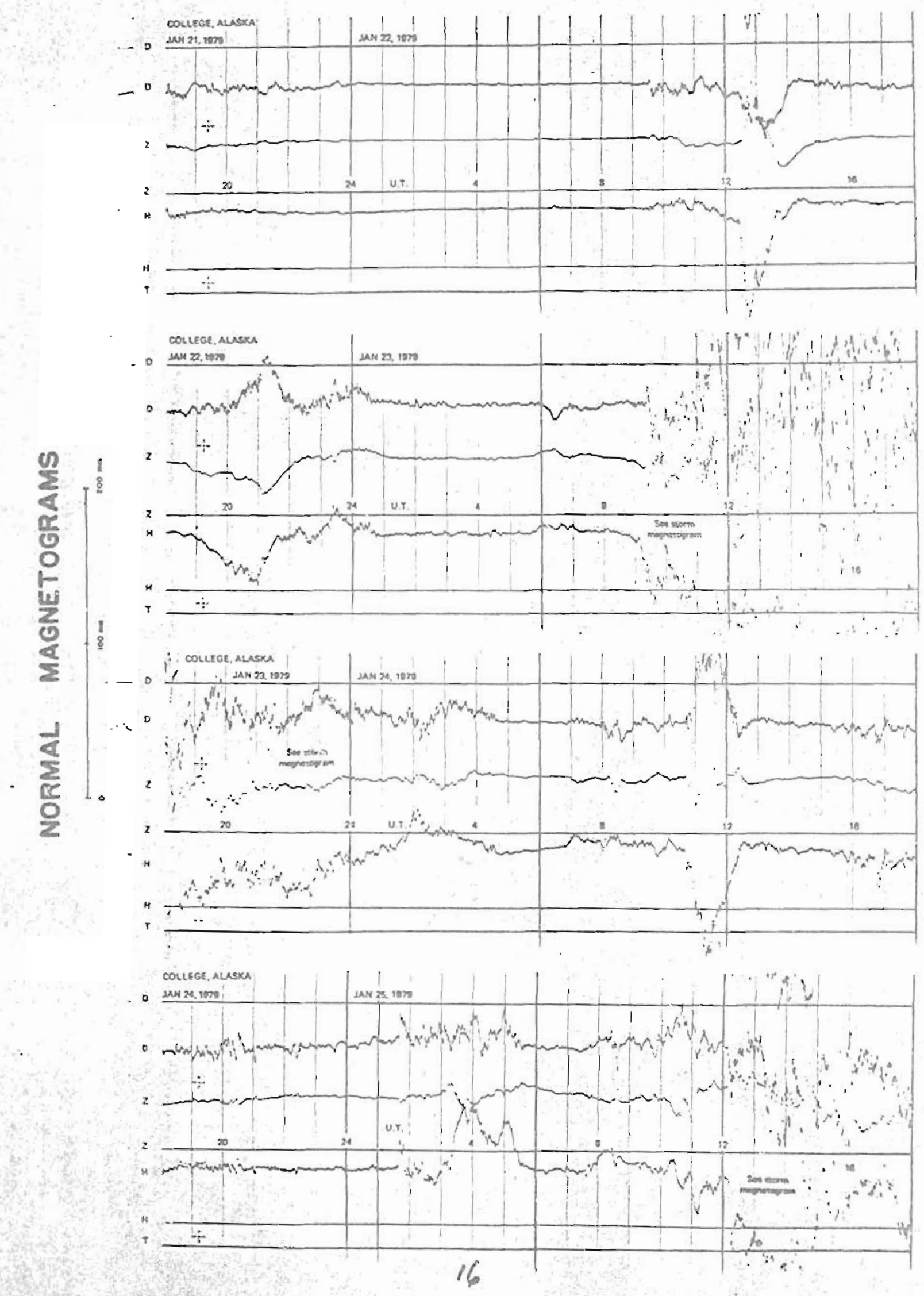



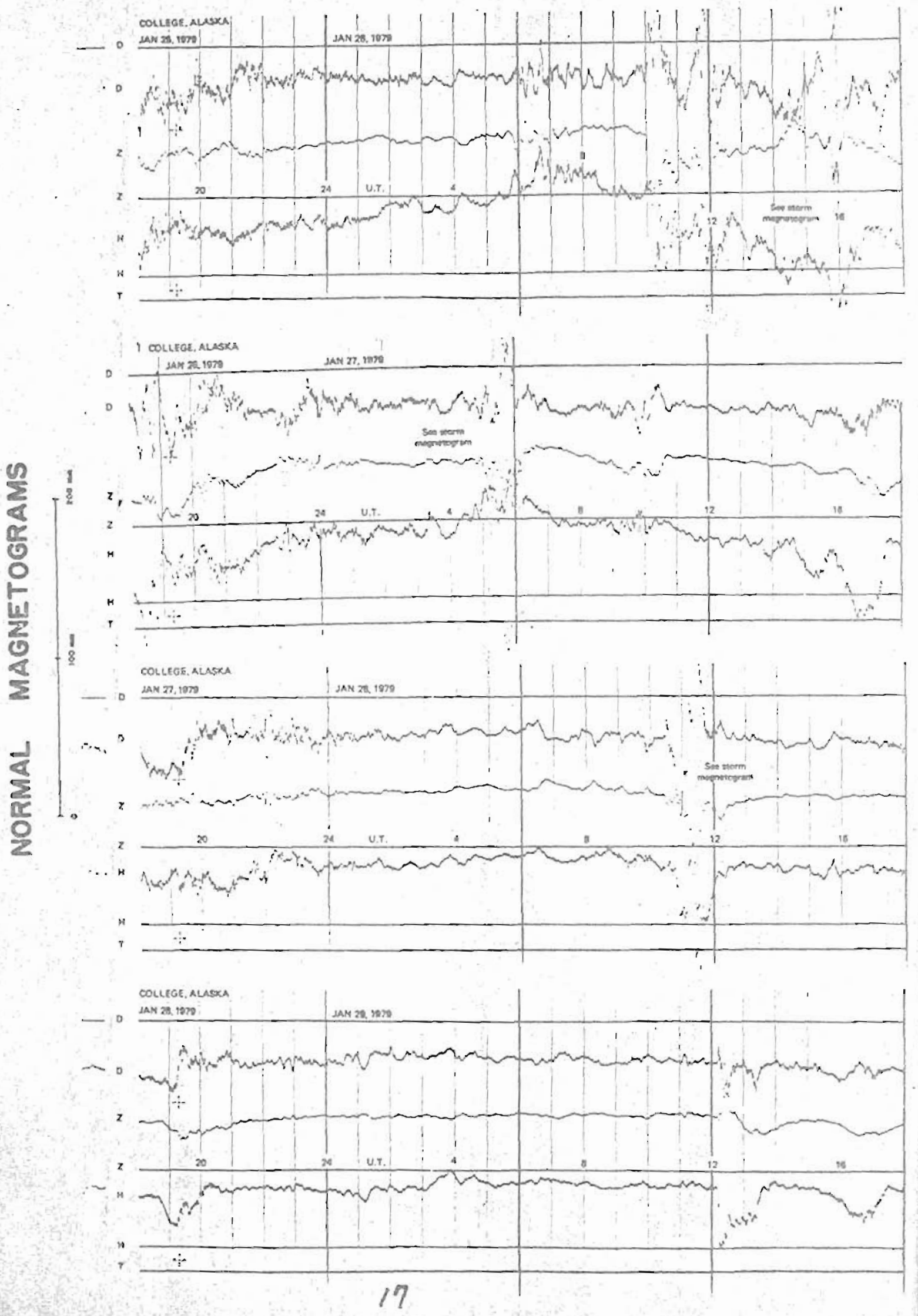

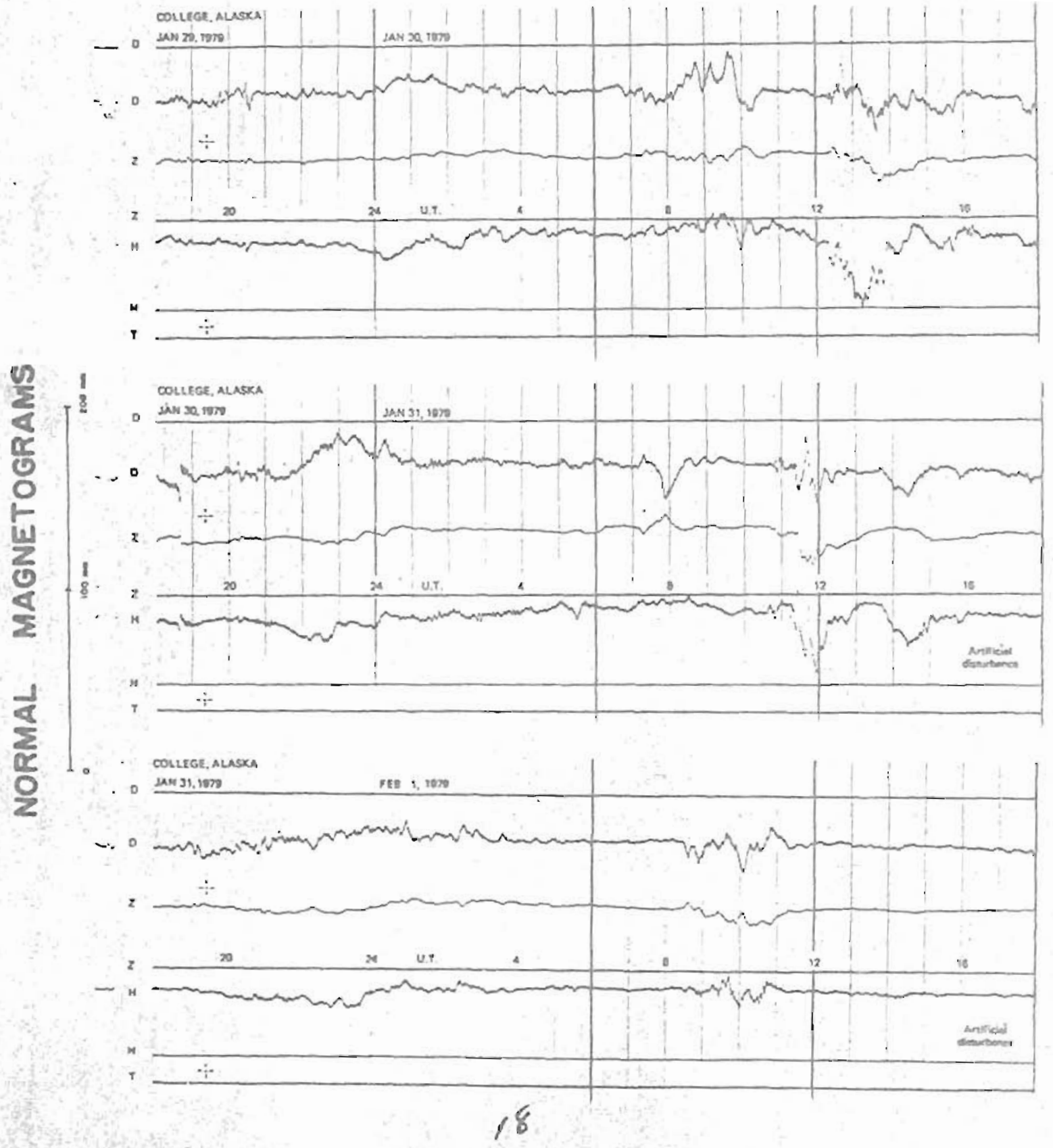


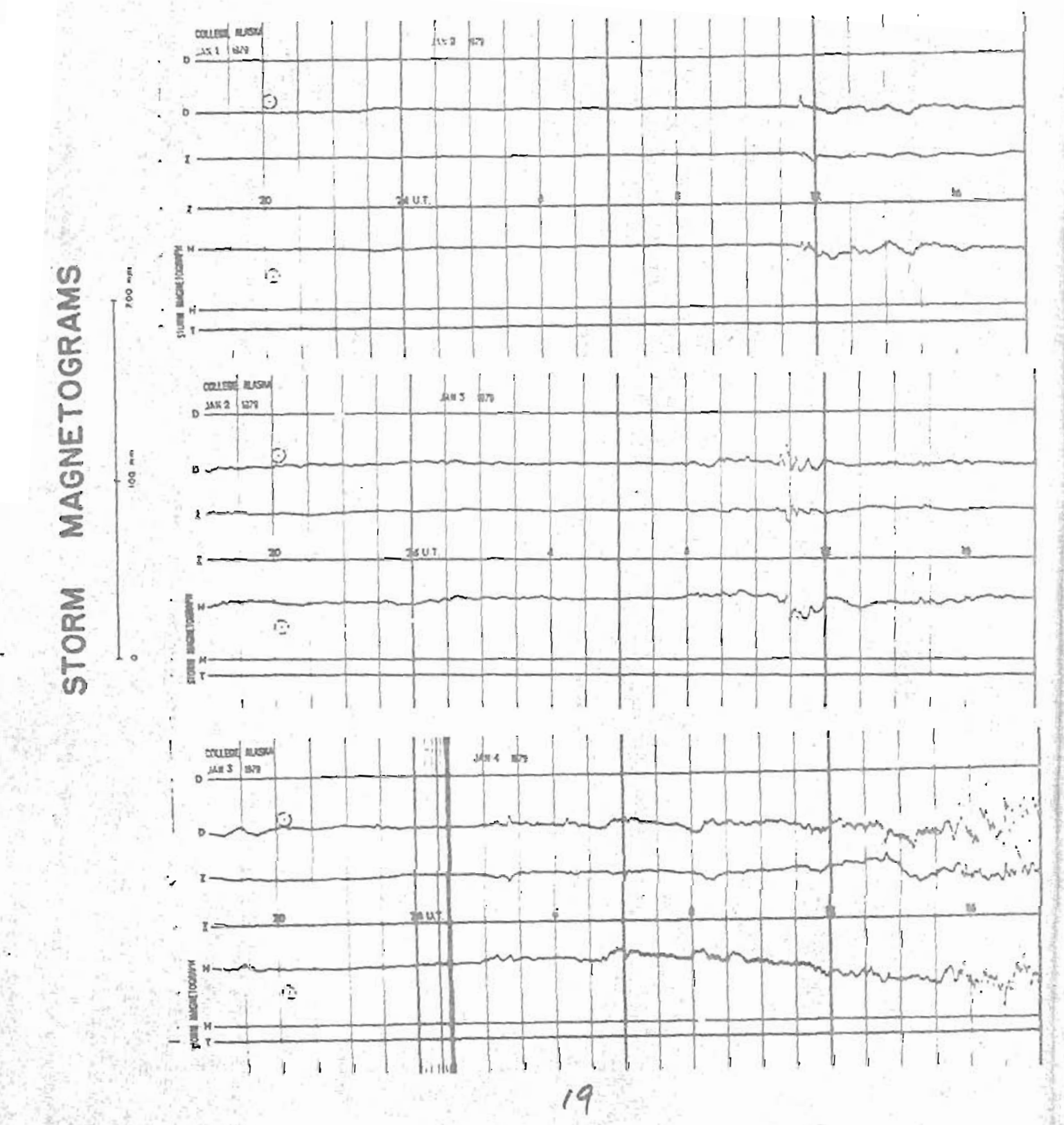




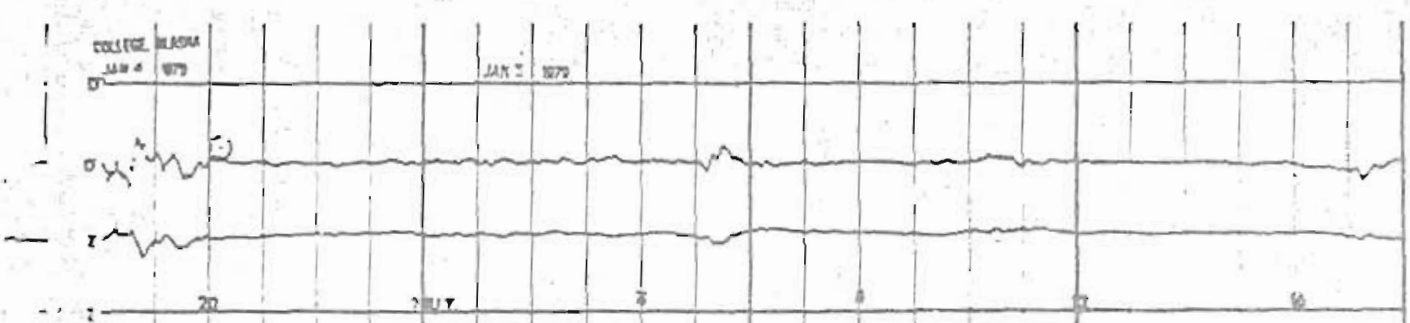

- Then

$-2$

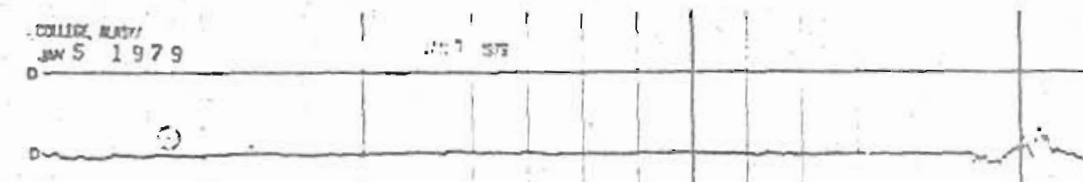
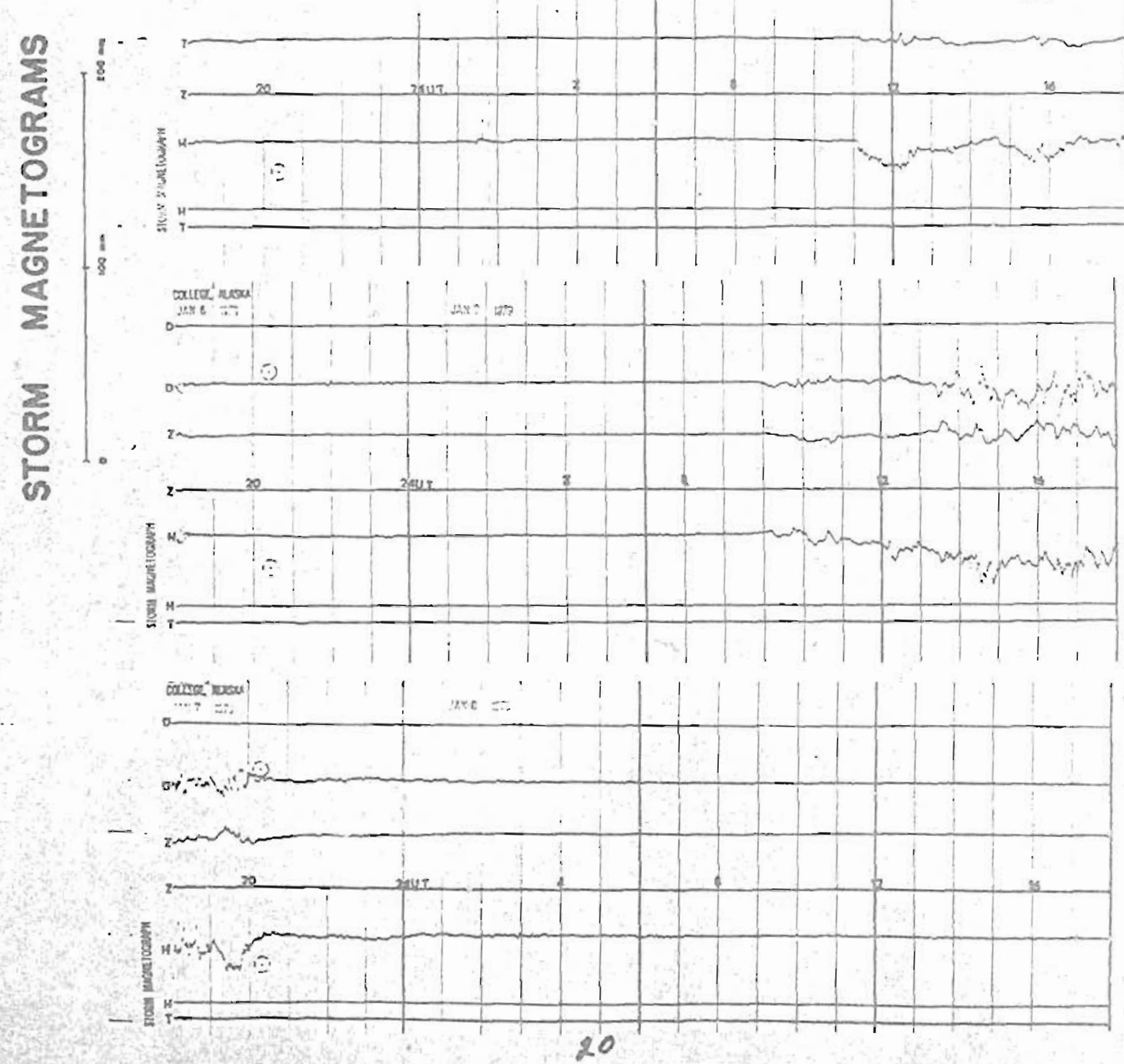

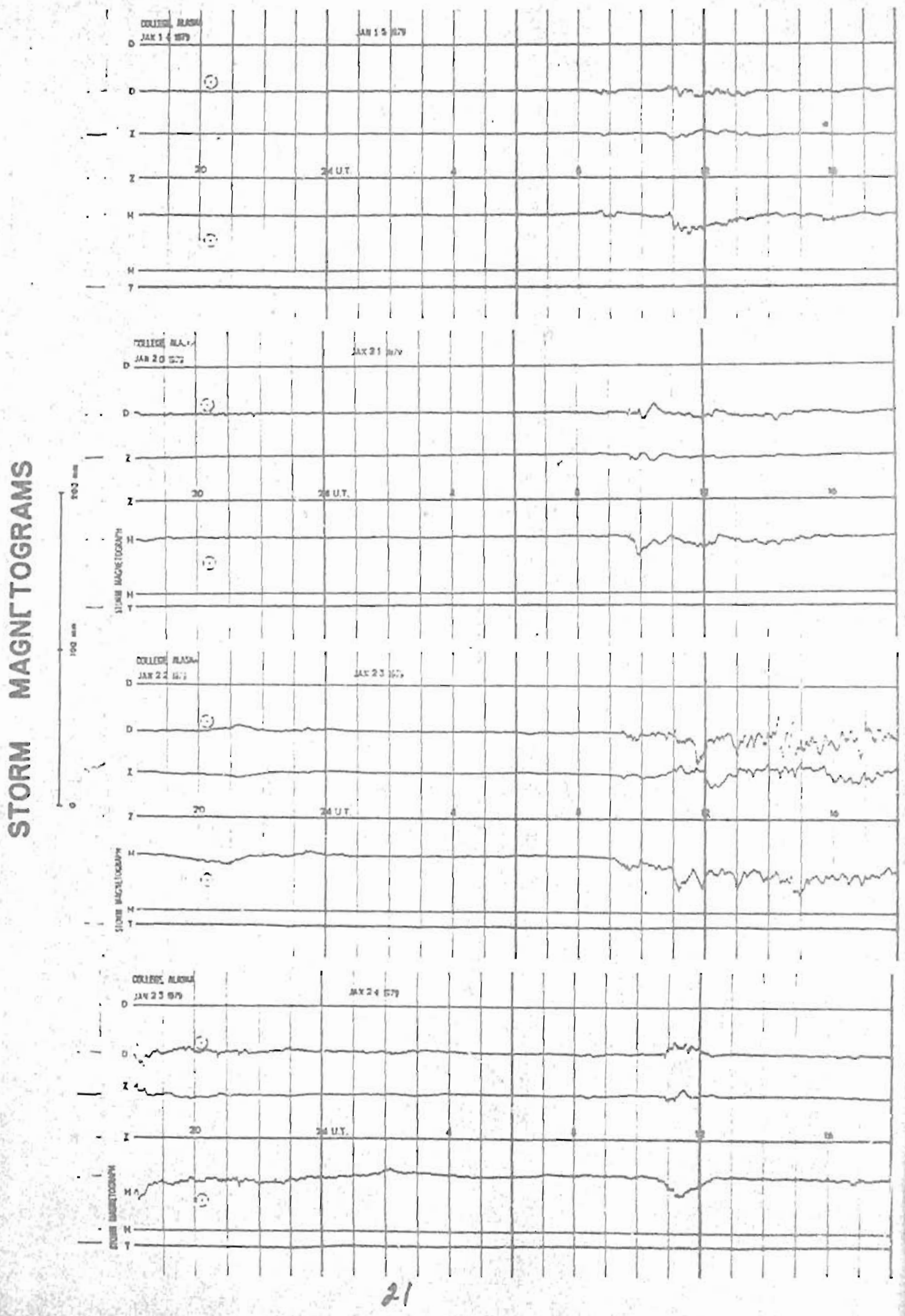

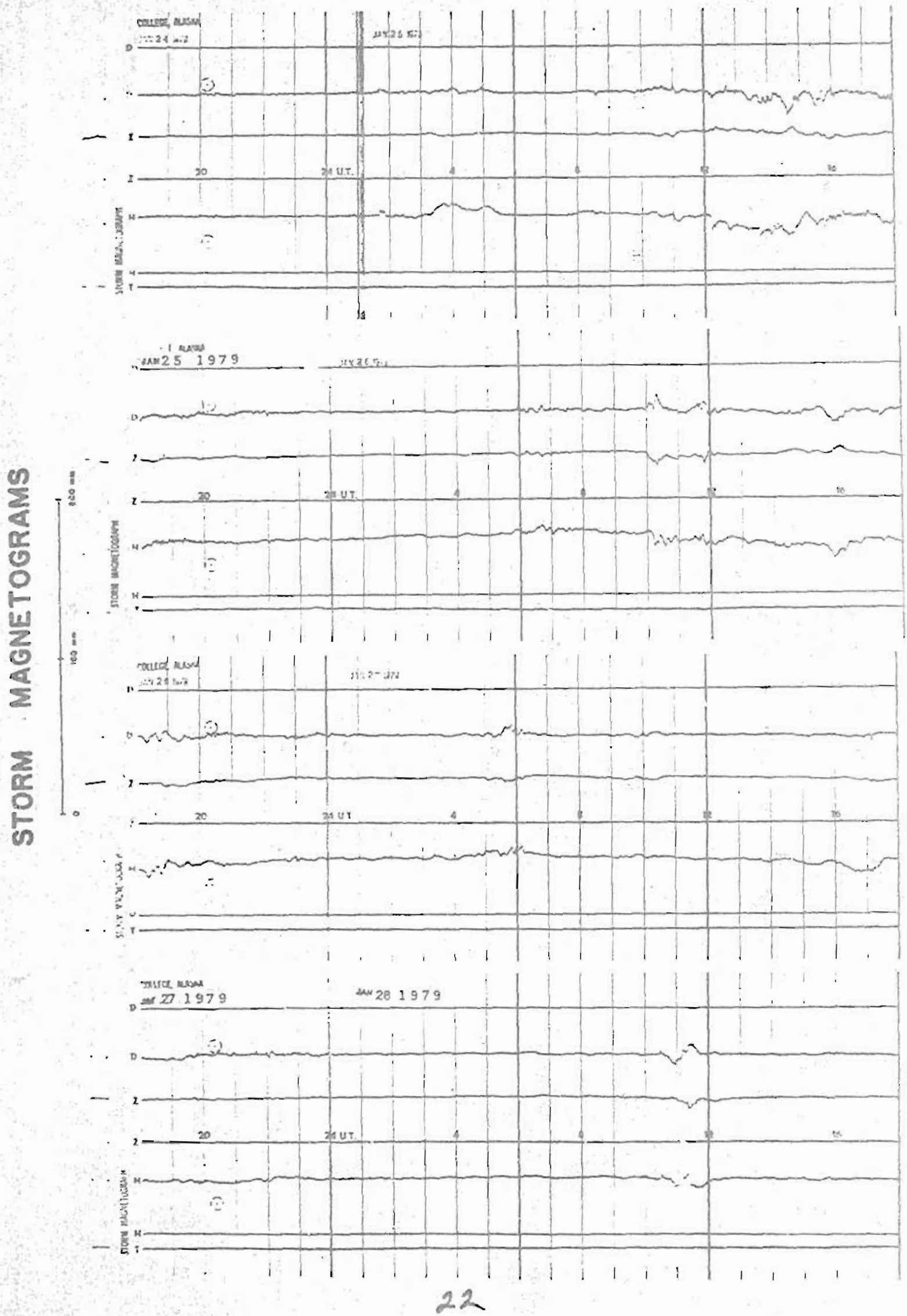